\title{
Fabrication of chitosan-polyvinyl alcohol and silk electrospun fiber seeded with differentiated keratinocyte for skin tissue regeneration in animal wound model
}

\author{
Afshin Fathi ${ }^{1}$, Mehdi Khanmohammadi ${ }^{2} \mathbb{D}$, Arash Goodarzi ${ }^{3}$, Lale Foroutani ${ }^{4}$, Zahra Taherian Mobarakeh ${ }^{5}$,
} Jamileh Saremi ${ }^{5}$, Zohreh Arabpour ${ }^{5,6}$ and Jafar $\mathrm{Ai}^{5,7^{*}}$

\begin{abstract}
Hybrid fibrous mat containing cell interactive molecules offers the ability to deliver the cells and drugs in wound bed, which will help to achieve a high therapeutic treatment. In this study, a co-electrospun hybrid of polyvinyl alcohol (PVA), chitosan (Ch) and silk fibrous mat was developed and their wound healing potential by localizing bone marrow mesenchymal stem cells (MSCs)-derived keratinocytes on it was evaluated in vitro and in vivo. It was expected that fabricated hybrid construct could promote wound healing due to its structure, physical, biological specifications. The fabricated fibrous mats were characterized for their structural, mechanical and biochemical properties. The shape uniformity and pore size of fibers showed smooth and homogenous structures of them. Fourier transform infrared spectroscopy (FTIR) verified all typical absorption characteristics of Ch-PVA + Silk polymers as well as Ch-PVA or pure PVA substrates. The contact angle and wettability measurement of fibers showed that mats found moderate hydrophilicity by addition of Ch and silk substrates compared with PVA alone. The mechanical features of Ch-PVA + Silk fibrous mat increase significantly through co-electrospun process as well as hybridization of these synthetic and natural polymers. Higher degrees of cellular attachment and proliferation obtained on Ch-PVA + Silk fibers compared with PVA and Ch-PVA fibers. In terms of the capability of Ch-PVA + Silk fibers and MSC-derived keratinocytes, histological analysis and skin regeneration results showed this novel fibrous construct could be suggested as a skin substitute in the repair of injured skin and regenerative medicine applications.
\end{abstract}

Keywords: Hybrid fiber, Chitosan, Poly vinyl alcohol, Silk, Mesenchymal stem cells, Keratinocytes, Electrospinning, Skin tissue regeneration

\footnotetext{
* Correspondence: jafar_ay2000@yahoo.com; Jafar_ai@tums.ac.ir

${ }^{5}$ Department of Tissue Engineering and Applied Cell Sciences, School of

Advance Technologies in Medicine, Tehran University of Medical Sciences,

Tehran 1417743361, Iran

${ }^{7}$ Brain and Spinal Cord Injury Research Center, Neuroscience Institute, Tehran University of Medical Sciences, Tehran, Iran

Full list of author information is available at the end of the article
}

(c) The Author(s). 2020 Open Access This article is licensed under a Creative Commons Attribution 4.0 International License, which permits use, sharing, adaptation, distribution and reproduction in any medium or format, as long as you give appropriate credit to the original author(s) and the source, provide a link to the Creative Commons licence, and indicate if changes were made. The images or other third party material in this article are included in the article's Creative Commons licence, unless indicated otherwise in a credit line to the material. If material is not included in the article's Creative Commons licence and your intended use is not permitted by statutory regulation or exceeds the permitted use, you will need to obtain permission directly from the copyright holder. To view a copy of this licence, visit http://creativecommons.org/licenses/by/4.0/ The Creative Commons Public Domain Dedication waiver (http://creativecommons.org/publicdomain/zero/1.0/) applies to the data made available in this article, unless otherwise stated in a credit line to the data. 


\section{Introduction}

Scaffolds are bioactive substrates that play vital role in tissue repair and regeneration since they could mimic components and structural perspectives of extracellular matrix (ECM) [1-4]. Scaffolds should not only possess suitable mechanical properties, but also need to imitate the structural aspects of natural ECM to create an ideal support for cell seeding, adhesion, proliferation as well as differentiation with least inflammatory and toxic reactions [1-3, 5-7]. Natural ECM consists of diverse interwoven protein fibers with nanometer diameters and nanoscale structure $[1,2,6,8]$. These nanoscale structures can support cell functions and direct cell fate $[1,2,6]$. In this regard, fabricating scaffolds with the same architecture of native tissues is one of the main challenges in this field $[1,2,6,8]$. Production of nanoscale scaffolds as ECM substitutes have been well developed in various methods including phase separation, selfassembly, synthetic molding, microfluidic and electrospinning [1, 2, 6, 9]. Among these, the electrospinning process has recently gained considerable attention because of its high degrees of processability, diverse applicability of biopolymers over other methods and capacity in mimicking extracellular matrix (ECM) structure with adjustable porosity and pore size distribution of fibers $[1,2,6,10]$. Furthermore, the large surface area of electrospun fibers and porous structure can extensively enhance cell viability and functionality $[1,2,6,11,12]$. Until now, the wide range of polymers are capable of being electrospun which shows flexibility in designing fibrous scaffolds from pure or blended of natural and synthetic polymers [1, $2,6,8,11-13$ ]. Natural polymers include collagen, fibrin, silk, carboxymethyl cellulose (CMC), hyaluronic acid (HA) and chitosan (Ch) which are actively interacted with cells through cell surface receptor ligands and in following cell-signaling pathways, but they are expensive, not easy accessible and have poor mechanical properties [1, 13-16]. By contrast, synthetic polymers provide great applicability by chemical or physical modifications and their excellent processability $[1,6,16,17]$. However, these polymers lack bioactivity and special care needs to be taken to ensure that newly synthesized polymers are biocompatible [1, $6,16,17]$. Poly vinyl alcohol (PVA) is food and drug administration (FDA) approved polymer for clinical use due to its degradability, cytocompatibility and processability as well as excellent strength and elongation properties $[1,5,6,8,18]$. Nevertheless, singlecomponent biopolymer is generally insufficient for good physical and biochemical fiber specifications [2, 14, 16, 19-21]. To overcome these limitations, recent effort has been given to takes advantage of the physical properties of the synthetic polymers and the bioactivity of the natural polymers while minimizing disadvantages of both combine for the preparation of electrospun fibers [2, 14, 16, 19-21].

Silk protein generated from silk cocoons has been extensively used for the medical applications including wound healing, tissue regeneration and drug delivery [5, 10, 22]. Silk derivatives contain high quantity of (GlyAla-Gly-Ser) $n$ sequences in the crystalline region, (Ala) $\mathrm{n}$ sequences as well as Arg-Gly-Asp tripeptide, which may function as a biological recognition signal and encourage cell adhesion [21-23]. Besides, Ch derivative as a biomimetic polymer owing to its hemostatic, stimulation of healing, antimicrobial, nontoxic, biocompatible and biodegradable properties has received significant status on wound healing and skin tissue regeneration [5, $6,19]$. Cell adhesion to $\mathrm{Ch}$ hydrogels and their degradation can be controlled by $\mathrm{N}$-acetylation. The $\mathrm{N}$ acetylglucosamine moiety in $\mathrm{Ch}$ is a structural feature also found in glycosaminoglycan (GAG), a component of native ECM. Since the properties of GAG include specific interactions with bioactive components and cells, this suggests that the analogous structure of $\mathrm{Ch}$ may mimic these bioactivities. It is expected that with combination of synthetic PVA and natural derived polymers including $\mathrm{Ch}$ and silk could provide proper microenvironment for cell proliferation and differentiation in skin regeneration.

In this study we have fabricated hybrid Ch-PVA + Silk fibrous mat in uniform size and desirable porosity, degradability and mechanical properties through coelectrospinning process for wound healing application in a full-thickness excisional animal model. The physical and chemical characteristics of Ch-PVA + Silk fibrous mat including pore size, porosity, tensile strength, degradability and hydrophilic properties were evaluated in vitro. The cellular attachment, morphology and proliferation on fabricated fibers were investigated during extended time of incubation. The differentiation potential of mesenchymal stem cell to keratinocyte performed using defined conditional media. The wound healing test involved using Ch-PVA + Silk fibrous mat seeded with MSC-derived keratinocytes was performed in rat animal models (an overview of this study is shown in Fig. 1).

\section{Materials and methods Materials}

Ch (low in molecular weight $(\mathrm{Mw})$, degree of deacetylation 75-85\%) was obtained from Shanghai Hanshare Industry Co., Ltd. Silk was obtained by following previous reported protocols [22]. Briefly, cocoons of mulberry Bombyx mori silkworm were heated in $0.5 \%(\mathrm{w} / \mathrm{v})$ sodium carbonate within $1 \mathrm{~h}$ followed by washing in distilled water through centrifugation at $4000 \mathrm{rpm}$ for 10 


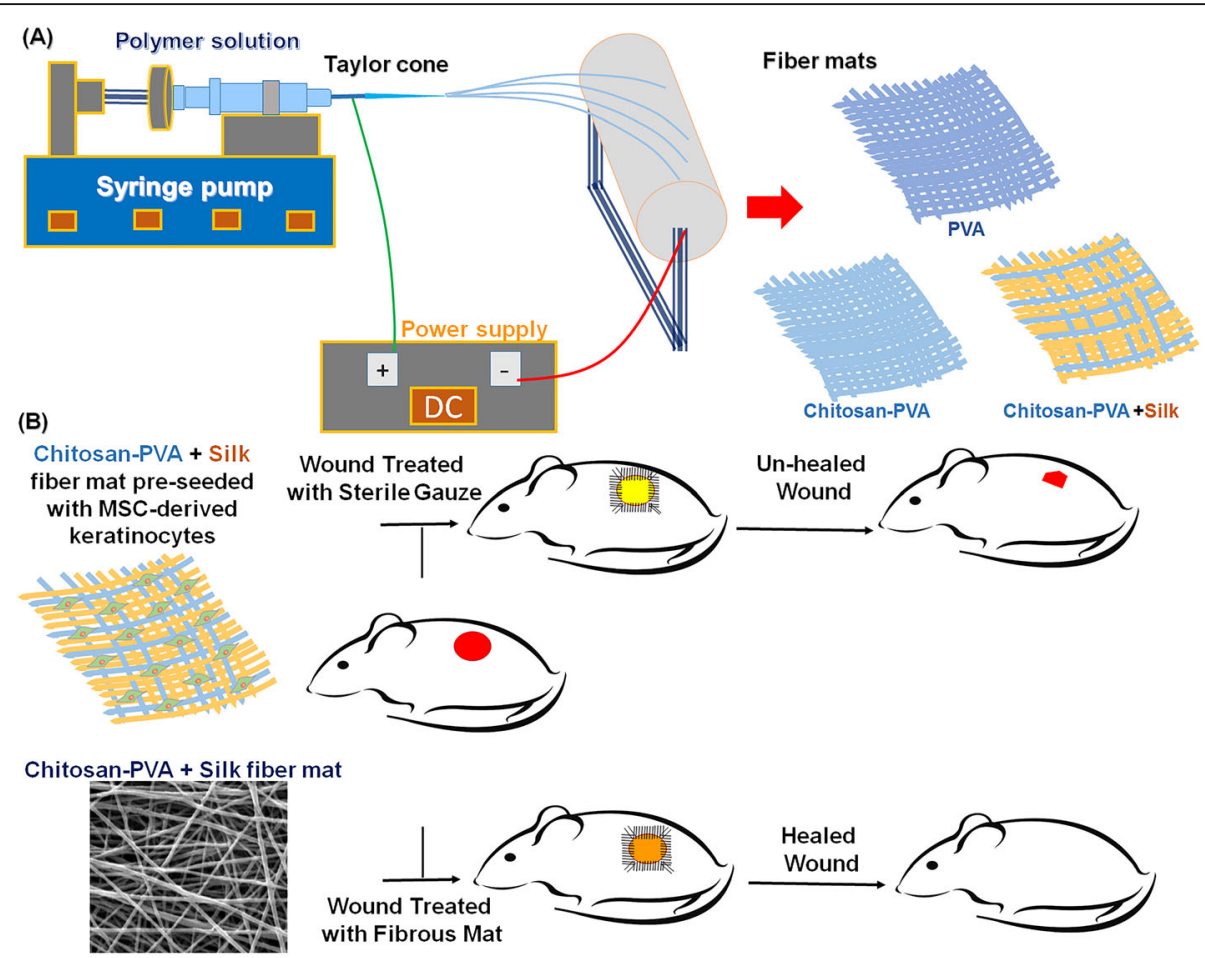

Fig. 1 Schematic representation showed (a) hybrid chitosan (Ch), polyvinyl alcohol (PVA) and silk fiber mat fabrication through electrospinning method and (b) its utilization in full-thickness wound 6 excision rat model to evaluate wound healing potential of transplanted Ch-PVA + Silk fibrous mat pre-seeded MSC-derived keratinocytes

min which help to remove debris. Degummed fibers were dried at room temperature and these fibers were dissolved in $9 \mathrm{M}$ of lithium bromide solution at $60^{\circ} \mathrm{C}$. The aqueous polymeric solution was dialyzing against deionized water and finally dried at $0.074 \mathrm{mb}$ and $53{ }^{\circ} \mathrm{C}$ for 2 days. The PVA (Mw: 85,000-124,000, $87-89 \%$ hydrolyzed), and all solvents, reactants and dialysis membrane (Mw: $12000 \mathrm{Da}$ ) were purchased from SigmaAldrich.

\section{Preparation of solvent and electrolyte solution PVA}

PVA solution of $10 \%(\mathrm{w} / \mathrm{v})$ was prepared by dissolving in distilled water at $85{ }^{\circ} \mathrm{C}$. The $\mathrm{Ch}$ was also dissolved in $0.01 \mathrm{M}$ acetic acid $\mathrm{pH} 4$ at a concentration of $2 \%(\mathrm{w} / \mathrm{v})$ under stirring for $1 \mathrm{~h}$. The silk solution of $10 \%(\mathrm{w} / \mathrm{v})$ was obtained by dissolving its powder in hexafluoroisopropanol 50\% (w/v). Then, PVA and Ch solutions were combined in a volume ratio of 9: 1 under magnetic stirring at ambient temperature to form a stable suspension. Then, the pure PVA or Ch-PVA mixture and silk solutions were electrospun (electrospray device; Gene Fanavaran Nanomeghyas, Iran) by $5 \mathrm{ml}$ syringe connected to stainless steel 21-gauge blunt ended needle in reverse direction at room temperature. The electrospinning factors were selected counter current co-electrospun process as follows: discharge rate for both solutions: 0.4 $\mathrm{mL} / \mathrm{h}$, voltage for PVA or Ch-PVA solution: $18 \mathrm{KV}$ and for silk solution: $14 \mathrm{KV}$, the distance between the tip of the needles and rotating wheel covered by aluminum foil for PVA or Ch-PVA solution: $20 \mathrm{~cm}$ and for silk solution: $15 \mathrm{~cm}$. To concentrate the fibers on the collector surface, other parts of the machine were insulated except for the place where the fabricating nanofibers were to be assembled by aluminum foil. The co-electrospinning process was stopped after $6 \mathrm{~h}$ running and electrospun fibrous sheets were crosslinked by contact with $50 \%$ glutaraldehyde in desiccator overnight. The fibrous mats were vacuumed for $2 \mathrm{~h}$ to remove any remained solvent before usage. The morphology of the initial electrospun fibers was investigated by conventional light microscopy for regular and nodal arrangement.

\section{Characterization of electrospun scaffolds}

The morphology and average diameter of fibrous mats were evaluated by a scanning electron microscopy (SEM, Philips XL30: Eindhoven, The Netherlands). The fabricated scaffolds were surface coated by gold layer using a sputter coater machine (Hummer 62, Ladd Research). The average diameter of the fabricated scaffolds was evaluated by image analysis software (Image J, NIH). 
Functional groups of fabricated fibrous scaffolds were evaluated using fourier transform infrared spectroscopy (FTIR). The FTIR spectroscopy was performed on a Bruker instrument (Aquinox 55, Germany) in the range of $400-4000 \mathrm{~cm}^{-1}$ and with a resolution of $1 \mathrm{~cm}^{-1}$. Distribution of prepared fibrous mat pores, porosity percentage and mean value of pore diameter was measured using mercury porosimetery. The change in swelling ratio as well as hydrophobicity of fabricated PVA based fibrous mats were evaluated by the swelling test and contact angle analysis. The fibrous scaffolds were cut and weighed at $1 \times 1 \mathrm{~cm}$ to evaluate the water uptake. Each sample was removed after $24 \mathrm{~h}$ immersion in simulated liquid (PBS, Gibco) and gently placed between two filter papers to remove excess water. The samples were then weighed and the degree of swelling or water absorption of each sample was calculated by the following formula:

Degree of swelling $(\%)=\left(\mathrm{W}_{\mathrm{st}}-\mathrm{W}_{\mathrm{dt}}\right) / \mathrm{w}_{\mathrm{dt}} \times 100$.

$\mathrm{W}_{\mathrm{st}}$ is the wet weight after immersion in PBS and $\mathrm{W}_{\mathrm{dt}}$ is the sample weight in the dry state before immersion. The experiment was repeated three times and the results were averaged. The degradability of fibrous mats was evaluated during extended time of incubation for swelled mats. The scaffolds were placed in $6 \mathrm{~mL}$ PBS and incubated at $37^{\circ} \mathrm{C}$ for 14 days. At specified intervals the samples were taken out from the buffer. The samples were washed with deionized water at room temperature to remove the dissolved inorganic salts. Then, those were then weighed $\left(\mathrm{W}_{\mathrm{t}}\right)$. The weight loss $\left(\mathrm{W}_{\mathrm{L}}\right)$ of the scaffold was calculated using the following formula for water absorption where $\mathrm{W}_{0}$ is swelled fiber weight.

$$
\mathrm{W}_{\mathrm{L}} \%=\left(\mathrm{W}_{\mathrm{t}}-\mathrm{W}_{0}\right) / \mathrm{W}_{0} \times 100
$$

Mechanical properties of the fibrous mats were measured by the tensile strength evaluation. To this, the dry rectangular sample mats were cut in $4 \times 1 \mathrm{~cm}^{2}$ in dimensions and fixed between the grips of the testing device (Santam, Karaj, Iran). The mats were stretched in the axial direction with the rate of $5 \mathrm{~mm} / \mathrm{min}$ and the ultimate tensile strength was obtained for samples.

\section{Isolation and culture of bone marrow mesenchymal stem cells}

NMRI mice aged 5 to 6 weeks were used for isolation and culture of bone marrow mesenchymal stem cells (bMSCs). The Mice were first scarified by cervical spine removal. The both humerus and tibia were soaked in hank's balanced salt solution (HBSS; Sigma, H6648) supplemented with $15 \%(\mathrm{v} / \mathrm{v})$ fetal bovine serum (FBS, Atlanta Biologicals) and penicillin/streptomycin (100 U $\mathrm{mL}^{-1}, 0.1 \mathrm{mg} \mathrm{mL}^{-1}$ ). Then bones were cut and bone marrow was removed by dulbecco's modified eagle's medium (DMEM) using a flushing insulin syringe. The isolated cells were placed into a $15 \mathrm{~mL}$ conical tube and after centrifugation, the bMSCs were cultured in a 25 $\mathrm{cm}$ tissue culture flask containing DMEM supplemented with $20 \% \mathrm{FBS}$ and antibiotics at $5 \% \mathrm{CO}_{2}$ and $37{ }^{\circ} \mathrm{C}$. The cell culture media was replaced every 3 days.

\section{Characterization of keratinocyte}

The harvested cells $1 \times 10^{5}$ cells at passage $3-4$ were incubated with specific monoclonal antibodies tagged with FITC directed against CD31, CD34, CD73, or CD105 for $30 \mathrm{~min}$ at room temperature. Stained cells were rinsed with phosphate buffered saline (PBS; pH: 7.4) and were fixed in $1 \%$ formaldehyde solution and studied using $\mathrm{BD}$ FACCS Calibur (BD bioscience San Jose, CA, USA). Furthermore, the differentiation potential of adherent fibroblastoid cells into keratinocyte lineage was performed as described previously $[24,25]$. For this, cells at density $1 \times 10^{5}$ were seeded in 6-well tissue plate and incubated in conditional DMEM media containing $2 \mathrm{mM}$ calcium chloride, $5 \mu \mathrm{g} / \mathrm{mL}$ insulin and $10 \mathrm{ng} / \mathrm{mL}$ recombinant human epidermal growth factor (EGF) and keratinocyte growth factor (KGF) when changing culture media every 3 days until 18 days. The cultured cells were evaluated via immonohistochemical staining after fixing with $4 \%$ formaldehyde. The cells were treated with specific keratinocyte antibodies for $15 \mathrm{~min}$ and after that stained samples were imaged under LABOMED TCM 400 microscope.

\section{Cell attachment and proliferation on Ch-PVA and silk fibrous mat}

The Ch-PVA and silk fibrous scaffold $1 \times 1 \mathrm{~cm}$ in size was immersed in $70 \%$ ethanol for $1 \mathrm{~h}$. To assure sterilization of fibrous scaffold, each side of sample was exposed ultraviolet light at $245 \mathrm{~nm}$ for $30 \mathrm{~min}$. The fibrous scaffold was then placed in 24-well tissue plate and were washed with PBS buffer. The MSC-derived keratinocytes were seeded at $1 \times 10^{4}$ cells on fibrous scaffold surface and incubated for $4 \mathrm{~h}$ to allow the attach cells on scaffold structure. The cellular attachment was evaluated by SEM analysis. To this, fibers with seeded MSC-derived keratinocytes were washed with PBS and cells were fixed on the these using $2.5 \%(\mathrm{w} / \mathrm{v})$ glutaraldehyde for $4 \mathrm{~h}$. Then, fibrous scaffolds were dehydrated through a graded ethanol series (50 to $95 \%(\mathrm{w} / \mathrm{v}))$, and then sputter-coated with gold. The cellular morphology was examined using a scanning electron microscope (SEM; Philips XL30, Netherland). Moreover, for qualitative evaluation of cell viability, cell seeded on fibrous scaffolds were treated with DAPI (4',6-diamidino-2-phenylindole) solution and incubated in dark condition for $15 \mathrm{~min}$. Then, samples were washed twice with PBS to 
remove non-reacted DAPI solution and examined by fluorescent microscopy.

\section{Cellular proliferation on Ch-PVA and silk fibrous mat} Cellular growth was evaluated by 3-[4,5-dimethyl-2thia-zolyl]-2, 5-diphenyl-2H-tetrazolium bromide (MTT) assay as well as DAPI staining for seeded MSC-derived keratinocytes on fibrous mats during extended time of incubation. For this, $0.5 \mathrm{~mL}$ DMEM media and $50 \mu \mathrm{L}$ MTT reagent were added to the samples and incubated for $4 \mathrm{~h}$ at $37^{\circ} \mathrm{C}$. The mitochondrial enzyme succinate-dehydrogenase within viable cells cleavages tetrazolium salt MTT into a blue-colored product (formazan). The formazan derivatives in medium was dissolved in $0.5 \mathrm{~mL}$ DMSO solution. The absorbance of each sample was measured using a spectrophotometer at $570 \mathrm{~nm}$. The quantity of formazan produced is correlated with the number of living cells in the sample.

\section{Wound healing model}

Twelve male Wister rats (average weight 200-250 g) were used for wound healing analysis. Animal experiments were carried out in compliance with the $\mathrm{Na}$ tional Institutes of Health (NIH Publication No. 8023, revised 1978) guidelines for the care and use of laboratory animals and approved by the local Ethics Committee of "Regulations for using animals in scientific procedures in Tehran University of Medical Sciences. Rats were anesthetized with intraperitoneal injection of ketamine 5\%/Xylazine 2\% (Alfasan Co., Woerden, Netherlands) and dorsal skin was shaved and cleaned with betadine solution. Full-thickness circular wound (including panniculus carnosus) was inflicted with 10 mm dermal biopsy punches on site of the shaved back. The wounds were washed with physiologic serum and the rats were randomly divided into three groups $(n=4$ in each group): paraffin sterile gauze, Ch-PVA + Silk, and Ch-PVA + Silk + MSC-derived keratinocyte groups. The density of MSC-derived keratinocytes was $2 \times 10^{5}$ cells which seeded on fibrous mat for $4 \mathrm{~h}$ prior suturing fibrous on wound site. The fiber scaffolds were sutured on wound sites using synthetic suture material and elastic adhesive bandage to fix the dressings. On day 14 postsurgery, all the wounds in each group were washed with physiologic serum and the animals were sacrificed for further analysis.

\section{Histopathology study}

Animals were euthanized 14 days' post-treatment and the skin tissues were harvested and immediately fixed in the $10 \%$ neutral buffered formalin (PH. 7.26) for $48 \mathrm{~h}$. Then the fixed tissue samples were processed by embedding in paraffin sheet, and sectioning in $5 \mu \mathrm{m}$ thickness. Finally, the sections were stained with haematoxylin and eosin (H\&E) and Masson's trichrome (MT). The histological slides were evaluated by the independent reviewer, using light microscopy (Olympus BX51; Olympus, Tokyo, Japan) and analyzed using image $j$ software. Epithelialization, inflammatory cell infiltration, fibroplasia, and granulation tissue formation have assessed in different groups, comparatively. Magnification $\times 400$ was employed for counting the cells and the calculation was repeated for six fields.

\section{Histomorphometry analysis}

Epithelialization was assessed semiquantitatively on 5 point scale: 0 (without new epithelialization), 1 (25\%), 2 (50\%), 3 (75\%), and $4(100 \%)$. Moreover, the number of inflammatory cells and newly formed blood vessels were recorded in each group. For these parameters, results were validated by a comparative analysis of one independent observer blinded to the treatment groups.

\section{Statistical analysis}

All experiments were carried out in triplicate for each condition. The data are shown as means \pm standard deviation (StDev). Statistical analysis was performed by Minitab 18 software (Minitab, Inc., State College, USA). Significant differences were shown as ${ }^{*} P$-value $<0.05$, *** $P$-value $<0.01$, whereas ns show $P$-value $>0.05$.

\section{Results}

\section{Morphology and structure of Ch-PVA and silk fiber}

Polymer solutions were continuously extruded from the tip of the needles in co-electrospinning process while drawing the polymer solutions towards the collector continues under the influence of the electric field. During process crystalline cone created and the jet thrown toward the collector observed $[1,2,5,8$, 11]. Smooth and uniform fibers with porous structure was fabricated from neat PVA. The fiber morphology did not change with addition of $\mathrm{Ch}$ and incorporation of silk solution in co-electrospinning process (Fig. $2 \mathrm{~b}$ and c). The produced Ch-PVA + Silk fibrous mat was bead-free and smooth without any branching in regular shape during the process and observation showed that blended fibers get greater fiber flexibility. The fibrous mats were tightly packed and highly entangled without node formation (Fig. 2a-c). While, the mean diameter of fiber mat produced from neat PVA was $842 \pm 205 \mathrm{~nm}$ (Fig. 2a). The diameters of composite Ch-PVA and Ch-PVA + Silk increased at $1070 \pm 340$ and $1200 \pm 321 \mathrm{~nm}$ respectively (Fig. $2 \mathrm{~b}$ and c). However, statistically there was no significant difference in size distribution or average diameter of fibrous mats 


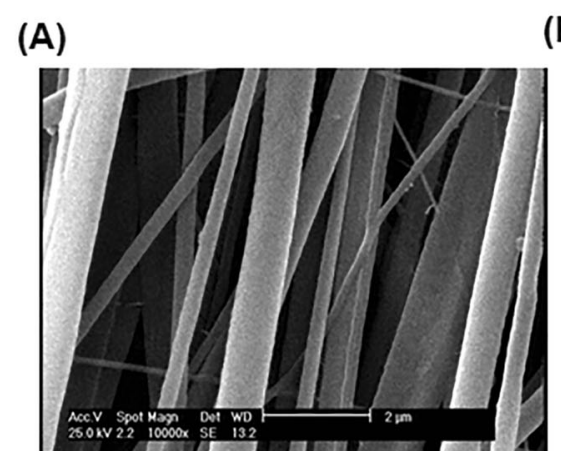

(E)

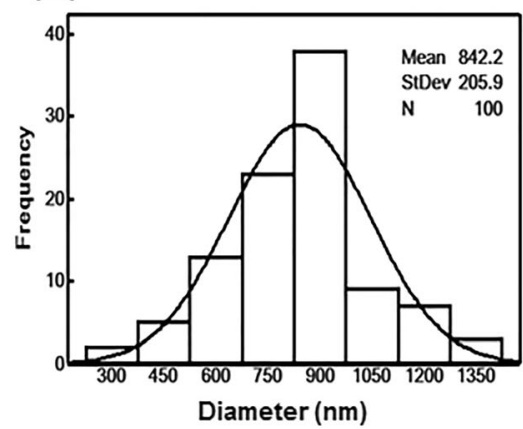

(B)

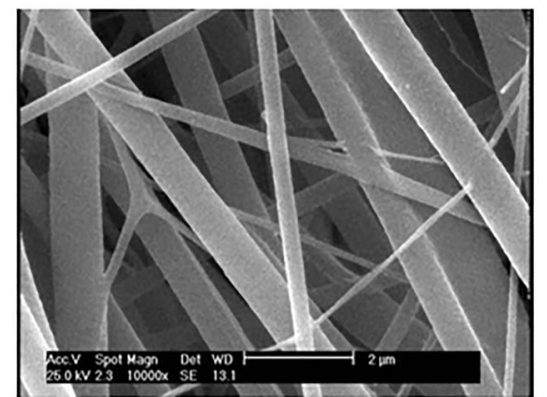

(F)

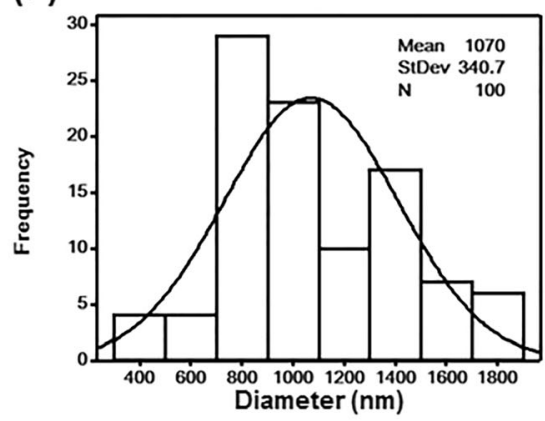

(C)

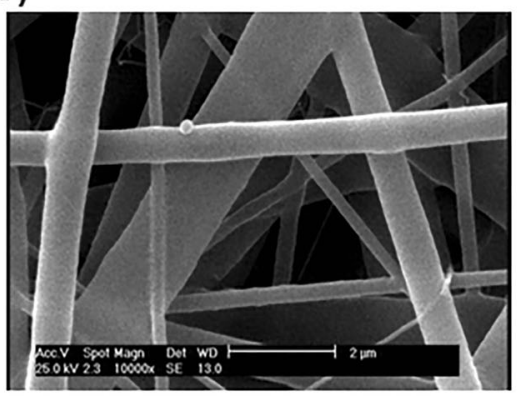

(G)

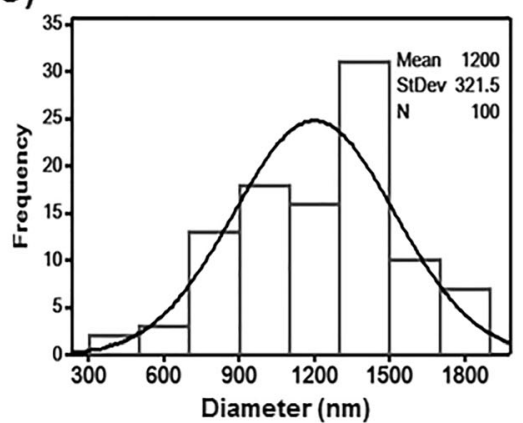

Fig. 2 SEM photograph $(\mathbf{a}, \mathbf{b}, \mathbf{c})$ and normal size distribution $(\mathbf{e}, \mathbf{f}, \mathbf{g})$ of nanofibers in different composition PVA (a, e), Ch-PVA (b, f), and ChPVA + Silk $(\mathbf{c}, \mathbf{g})$

in different compositions (Fig. 2e, $\mathrm{f}$ and $\mathrm{g}$ ). These proved that suitable concentration and ratio of polymers as well as applied voltage in agreement with previous studies $[2,5,8,11]$. In order to achieve a good electrospun fiber scaffold, suitable concentration of polymer and solubility in solvent are vital parameters to obtain homogenous, continuous and uniform size specimen which could result lack of phase separation traces $[1,2,5,8,11]$. Meanwhile, the average pore sizes of PVA and Ch-PVA were $1.33 \pm 0.49$ and $0.9 \pm 0.31 \mu \mathrm{m}$. The mean pore size of Ch-PVA + Silk fibrous mat was $2.2 \pm 0.9 \mu \mathrm{m}$ which indicated better pore size for permeation of oxygen and metabolites (Table 1). The Ch-PVA + Silk fiber had a porosity of $68 \pm 4.4 \%$ of the total scaffold volume in comparison with $74 \pm 3.9 \%$ and $52 \pm 4.7 \%$ for neat PVA and hybrid Ch-PVA fibrous mats (Table 1 ). The high porosity of the PVA fiber is desired due to ease transfer of nutrients, oxygen and other metabolites as well as support moisture and hydrophilicity of structure. Moreover, the pore size and interconnectivity of pore network would be facilitated cellular migration and in following angiogenesis which is important in wound healing and tissue engineering. The smallest pore size and porosity of fiber mat found for Ch-PVA fiber which could be due to water solubility of polymers as well as proper selection of processing parameters $[5,8,14$, $21,26]$.

\section{FTIR spectroscopy}

Figure 3 showed the FTIR spectrums of the fabricated PVA fiber. The peaks of PVA were revealed by the bands 829, 1110, 1731, 2925 and $3185 \mathrm{~cm}^{-1}$ for vibration stretching of $\mathrm{C}-\mathrm{C}$ in alkyl chain back bone, $\mathrm{C}-\mathrm{O}$ stretching, $\mathrm{C}=\mathrm{O}$ stretching, $\mathrm{C}-\mathrm{H}$ of alkyl stretching mode and $\mathrm{OH}$ vibrations respectively. The FTIR spectrum of ChPVA fiber mat showed a broad peak at $3338 \mathrm{~cm}^{-1}$, attributed to the $\mathrm{O}-\mathrm{H}$ and $\mathrm{N}-\mathrm{H}$ stretching vibrations which shifted to the higher wave number with addition of Ch to PVA materials (Fig. 3). The resonance band at 1645 and $1512 \mathrm{~cm}^{-1}$ related to amide $\mathrm{I}$ band $(\mathrm{C}=\mathrm{O}$ stretching) and amide II ( $\mathrm{N}-\mathrm{H}$ bending and $\mathrm{C}-\mathrm{H}$ stretching). Additionally, the pair peaks of 1129 and $921 \mathrm{~cm}^{-1}$

Table 1 Characterization of produced nanofibers in different composition

\begin{tabular}{llll}
\hline Composition & Mean diameter $(\mathbf{n m})$ & Pore size $(\boldsymbol{\mu m})$ & Porosity $(\%)$ \\
\hline PVA & $842 \pm 205$ & $1.33 \pm 0.49$ & $74 \pm 3.9$ \\
Ch-PVA & $1070 \pm 340$ & $0.9 \pm 0.31$ & $52 \pm 4.7$ \\
Ch-PVA + Silk & $1200 \pm 321$ & $2.2 \pm 0.9$ & $68 \pm 4.4$ \\
\hline
\end{tabular}




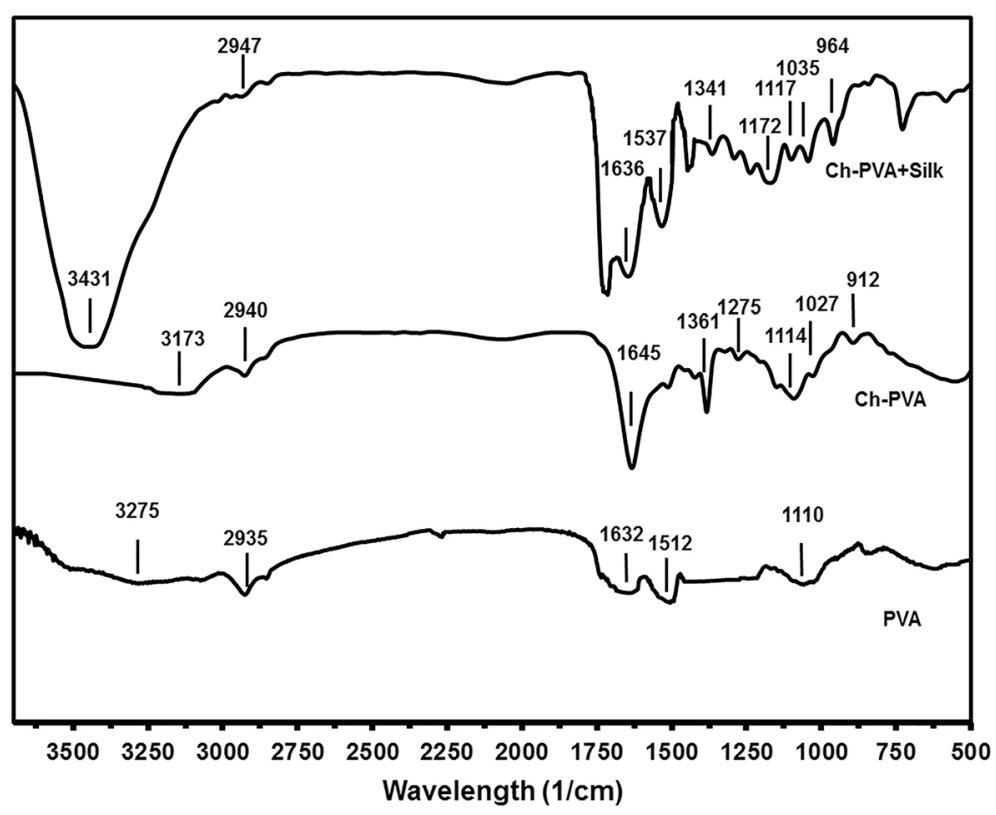

Fig. 3 FTIR spectrum of scaffold substrates including PVA, Ch-PVA, Ch-PVA + Silk

were arising from saccharide structure of $\mathrm{Ch}$ and also 1089 and $1027 \mathrm{~cm}^{-1}$ were related to the skeletal vibrations of $\mathrm{C}=\mathrm{O}$ stretching of the glucosamineresidues. The main characteristic absorption bands at $1636 \mathrm{~cm}^{-1}$ and $1537 \mathrm{~cm}^{-1}$ corresponded to amide $\mathrm{I}, \mathrm{C}=\mathrm{O}$ stretching and for amide II, secondary $\mathrm{N}-\mathrm{H}$ bonding due to b-sheet structure in silk structure. The peaks at $1341 \mathrm{~cm}^{-1}$ and $727 \mathrm{~cm}^{-1}$ assigned for amide III, C-N and N-H functionalities and for amide $\mathrm{V}$ respectively. The created fiber structure in Ch-PVA + Silk are due to intermolecular hydrogen bonds which occur between the hydroxyl group in PVA and the $-\mathrm{N}-\mathrm{H} / \mathrm{C}=\mathrm{O}$ bonds in grafted $\mathrm{Ch}$ and silk. However, noted shifts were not detected in the FTIR as there was no functional group alternation in the composite fiber. The FTIR spectroscopy could detect presence of the chemical bonds of specific polymers utilized for composite Ch-PVA + Silk fibrous mat.

\section{Swelling and hydrophilicity}

Hydrophilic/hydrophobic property of hydrogel manipulates cellular behavior including cell attachment, proliferation and migration potential through permeation of nutrient, metabolites and oxygen $[5,8,10$, 14]. Moreover, wettability of dressing area is an
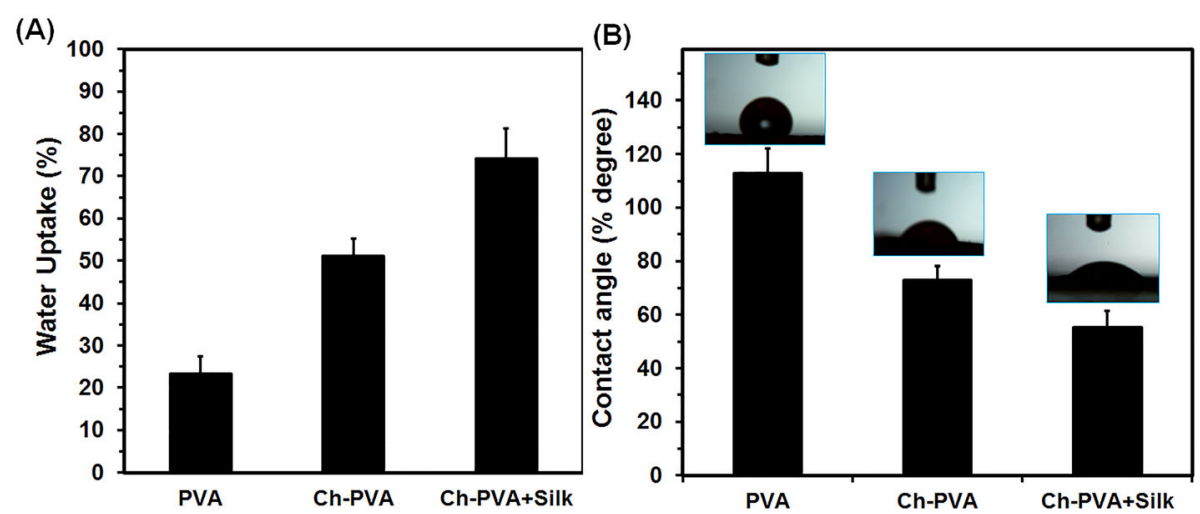

Fig. 4 Analysis of resultant PVA, Ch-PVA, Ch-PVA + Silk fiber mats. a wettability, (b) contact angle, (Vertical bars: standard deviations; StDev, $n=4)$ 
important element to maintain tissue moisture during wound healing process $[5,8,10,14]$. The PVA fiber showed trivial water absorption at $21 \%$ of initial weight of fiber (Fig. 4a). The hybrid fibers of ChPVA and Ch-PVA + Silk absorbed water molecules up to 51 and $74 \%$ respectively which indicate addition of $\mathrm{Ch}$ and silk could improve swelling behavior of fibers (Fig. 4a). High water absorbency of hydrogel fibers containing $\mathrm{Ch}$ and silk could be due to hydrogen bonding among polymeric chains and water molecules $[1,5,6,10,14,27]$. The hydrophilic functional groups in polymeric structure of ChPVA + Silk such as amine $\left(\mathrm{NH}_{2}\right)$, hydroxyl $[-\mathrm{OH}]$, amide $\left(-\mathrm{CONH}-,-\mathrm{CONH}_{2}\right)$ and sulphate $\left(-\mathrm{SO}_{3} \mathrm{H}\right)$ would be improved swelling degree of fibers $[5,10$, 14, 27]. As seen in Fig. 4b, average contact angles of the fibers decreased by hybridization pf polymers from $112^{\circ} \pm 8.1^{\circ}$ for neat PVA until $54^{\circ} \pm 6.4^{\circ}$ for hybrid Ch-PVA + Silk fibers which means higher hydrophilic characteristics of resultant fibers. The utilization of $\mathrm{Ch}$ and silk enhanced hydrophilic characteristic of fibrous mats owing to the presence of hydrophilic groups of $\mathrm{Ch}$ and silk on their structures and also Wenzel wetting model that occurs on heterogeneous surface geometries $[26,28]$. The $\mathrm{Ch}$ and silk could circumvent poor hydrophilicity of PVA fiber and provide desirable microenvironment for cell culture, tissue engineering as well as wound healing application $[5,8,14,21,27,28]$.

\section{Mechanical property and degradability}

Blending of PVA with Ch or incorporation of silk have an obvious impact on the mechanical properties of PVA fibrous mats (Fig. 5a-c). Mechanical strength and Young's modulus of PVA based fibrous mat reduced by admixing $\mathrm{Ch}$ to the PVA solution (Fig. $5 \mathrm{a}$ and $\mathrm{b}$ ). The Ch-PVA + Silk fibrous mat exhibited improvement in mechanical strength and Young's modulus with incorporation of co-electrospinning silk and these values were more than two times of results of PVA or Ch-PVA fibrous mat (Fig. 5a and b). Although, porosity and average pore size of Ch-PVA fibrous mat was lower than PVA fiber which means tight fiber network. However, the results suggest that chemical interaction of coelectrospun silk and blended Ch with PVA could be reason of enhanced strengthening $[5,12,20]$. The PVA fiber mat was break at about $100 \%$ elongation. The breaking strain of fibers was found to increase from around 100 to $220 \%$ upon utilization of $\mathrm{Ch}$ and silk in composite fibrous mat (Fig. 5c). Degradation of fibrous mat is important parameter in applicability of tissue engineering scaffolds which allow cell proliferation, migration and extracellular matrix replacement during cellular growth $[2,12,14,19,20,28]$. The neat PVA fiber mat showed lowest rate of weight loss compared to Ch-PVA and Ch-PVA + Silk mats (Fig. 5d). The weight loss of PVA specimen was lower than $20 \%$ until 14 days. The hybrid fibers comprising Ch-PVA and Ch-PVA + Silk mats showed an accelerated weight loss at about three and two
(A)

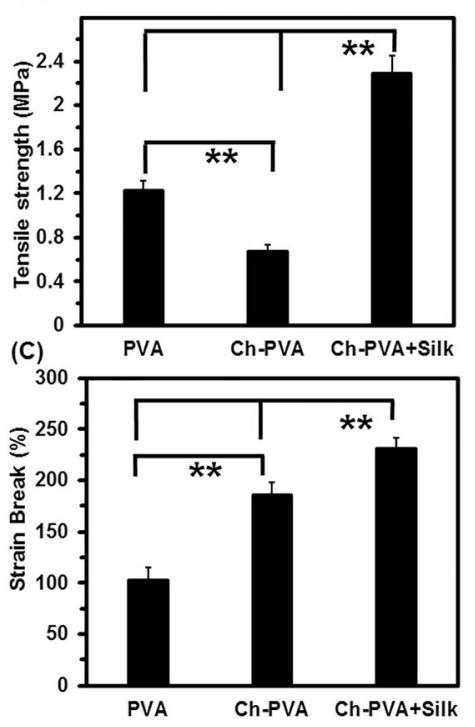

(B)

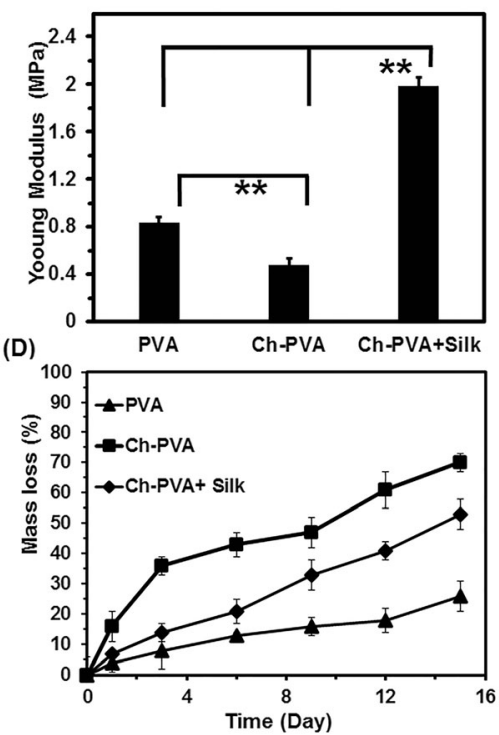

Fig. 5 Analysis of resultant PVA, Ch-PVA and Ch-PVA + Silk fiber mats including (a) tensile strength, (b) young modulus, (c) strain break (d) in vitro degradation rate. (Vertical bars: standard deviations; SDs, $n=5$ ) 
times compared with PVA sample until 14 days (Fig. 5d). The Ch-PVA can be easily dissolved and hydrolyzed in aqueous media. Meanwhile, incorporation of silk in ChPVA+ Silk fiber due to highly fibroin $\beta$ sheet in the silk structure resulted slower degradation compared with ChPVA fiber mat [10, 27]. These results would be confirmed by corresponding mechanical stiffness and hydrophilicity behavior of produced fibrous mats.

\section{Stem cell characterization and differentiation}

Isolated MSCs on culture dish could be adhered to dish culture and totally were spread and elongated in homogenous shape and morphology (Fig. 6a). Presence of MSC markers including CD73 and CD105 and the absence of endothelial cell marker CD31 as well as hematopoietic stem cell marker CD45 confirmed by flow cytometry analysis of the MSCs with specific antibodies Fig. 6b [3, 29-31]. Therefore, flow cytometry verified the bMSC characteristics for isolated cells. To induce keratinocyte differentiation of MSCs in long-term cultures, the isolated cells were exposed specific differentiating media [32, 33]. The MSC differentiation observed by phase contrast microscopy and immunocytochemical analysis compare with mice foreskin-derived keratinocytes as a positive control (Fig. 6a and c). The microphotograph shows evidences of polarization in the treated cells with differentiating media on day 18 and cells were in polygonal and cobblestone morphology with colonies likewise foreskin-derived keratinocytes which is specification of keratinocyte (Fig. 6a). As shown in Fig. 6c the differentiated MSCs into keratinocytes were positively expressed keratinocyte proteins including cytokeratin-19 (CK-19), involucrin (IVL) and vimentin (Vim) markers after 18 days in conditioned culture media similar results with foreskin-derived keratinocytes. It can be seen MSCs were negative to express CK19, IVL and Vim in undifferentiated media and did not expressed essential keratinocyte proteins. The utilization of calcium stimulus and EGF which bind to EGF receptor triggering signals was reliable approach for isolated MSC differentiation into keratinocytes. These data support the possibility of wider applications of MSCs for tissue engineering of skin through evidence for epidermal differentiation induction.

\section{Cell viability and proliferation}

To evaluate the biocompatibility of fabricated fibrous mats, cell culture experiments were performed by seeding MSC-derived keratinocytes on samples. The cellular morphology and metabolic activity of cells detected by SEM, DAPI staining and MTT assays for seeded cells on fibrous mats as well as polystyrene tissue culture plate (PS; control). Electronic microscopy photographs showed that cells attached, grew and spread extensively with cytoskeleton extension on the Ch-PVA and Ch-PVA + Silk fibrous mats (Fig. $7 \mathrm{a}$ and $\mathrm{b}$ ) which proves $\mathrm{Ch}$ and silk might be appropriate structure for cell culture systems [5, 34]. Whereas, the MSC-derived keratinocytes on PVA fibrous mat did not attached and were in spheroid shape (Fig. 7c). As can be seen, there were no significant differences between the cell viability of PVA and Ch-PVA fibrous mats in initial time of culture (Fig. 7d). The Ch-PVA + Silk and polystyrene tissue culture plate (PS) conditions showed higher number of attached cells in initial time of culture at $12 \mathrm{~h}$. Interestingly, viability of MSC-derived keratinocytes enhanced during extend time of incubation for ChPVA + Silk fibrous mat and cellular growth was reached 3 times higher than neat PVA fibrous mat group (Fig. $7 \mathrm{~d}$ ). The cells could maintain their viability on PVA and Ch-PVA during extended time of incubation and lower cellular growth could be due to lack of sufficient cell adhesive ligands in these fibrous mats. However, cells seeded on PS showed higher value compared with other cell seeded fibrous mat conditions (Fig. 7d). Besides, as seen in Fig. 7eg, composite Ch-PVA + Silk mats showed higher number of viable cells and their accumulation using dapi staining which confirmed proliferation of MSCderived keratinocytes. Results in desired cell proliferation could be due to existence of cell recognition signals as well as hydrophilic surface tendency of Ch-PVA + Silk fibers (Fig. 4a and b) $[3,7,16,27,28$, 32, 35]. In summary, these data substantiated that Ch-PVA + Silk fibrous mat possessed proper cytocompatibility and incorporation of $\mathrm{Ch}$ as well as silk resulted increase in cell adhesion and proliferation. Hence, hybrid Ch-PVA + Silk fiber revealed high biocompatibility and potential applicability for wound healing and tissue engineering applications (Fig. 7).

\section{Wound closure evaluation and histological analysis}

Due to proper in vitro results of Ch-PVA+ Silk fiber mat (Fig. 7), this fiber construct was utilized for in vivo wound treating experiments. We performed in vivo wound treating experiments using paraffin sterile gauze (as a negative control; Ctrl), and ChPVA + Silk fiber with and without MSC-derived keratinocytes for 14 days. The wound sizes show treatmentdependent and time-dependent differences in rate of wound contractions as indicated in Fig. 8a. The wound closure measurements indicated significant wound healing after 7 days treating by Ch-PVA + Silk fibrous mat with and without MSC-derived keratinocytes compared to paraffin sterile gauze condition (Fig. 8a). 
(A)

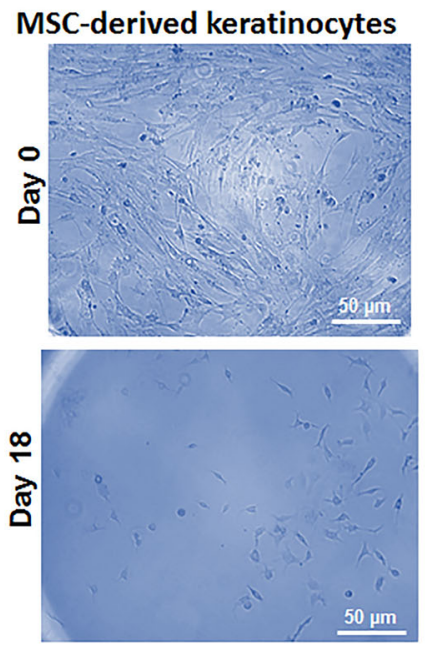

Fore-skin keratinocytes (Positive control)

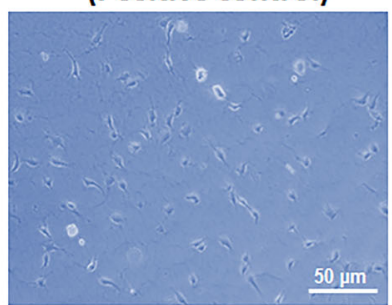

(C)
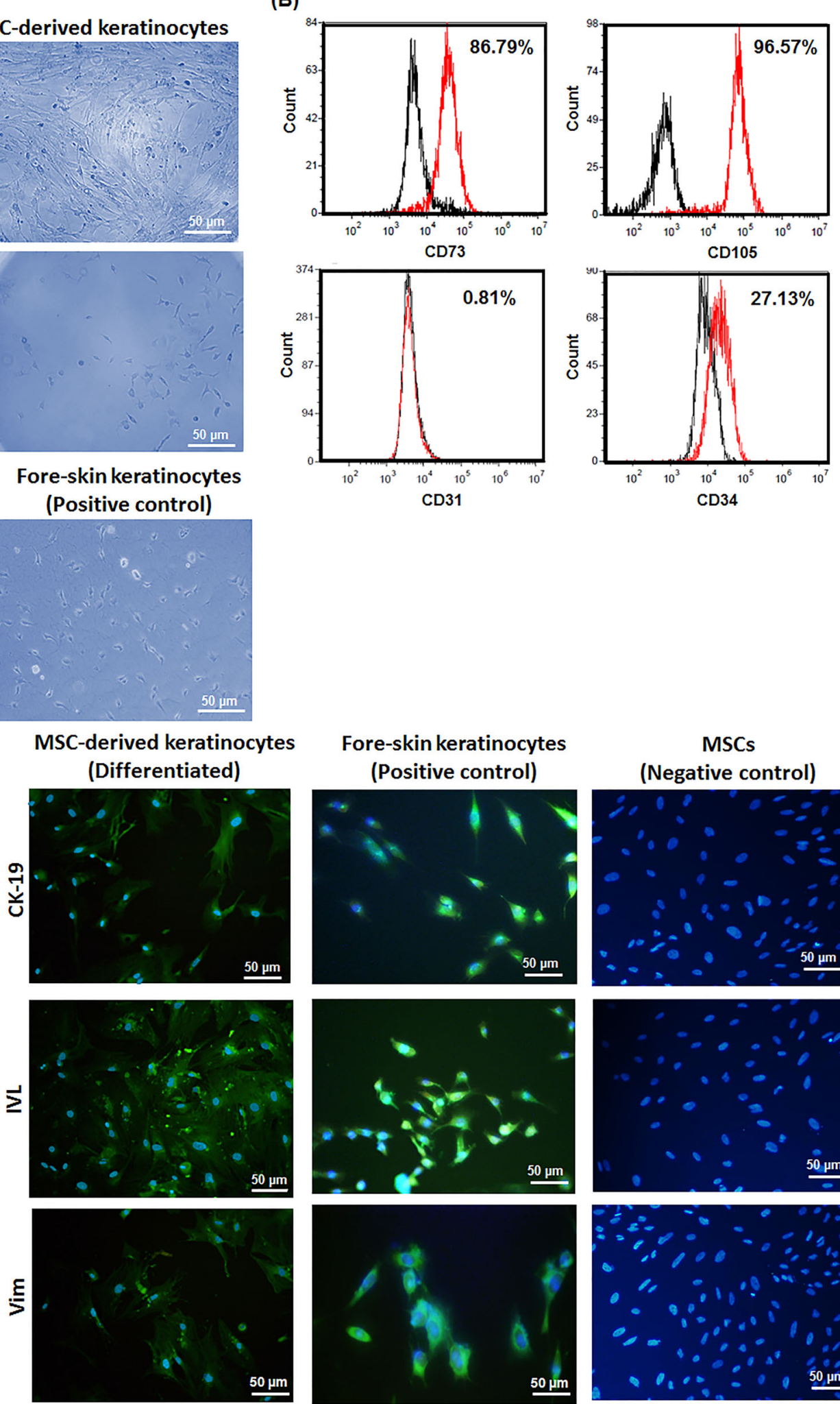

Fore-skin keratinocytes (Positive control)
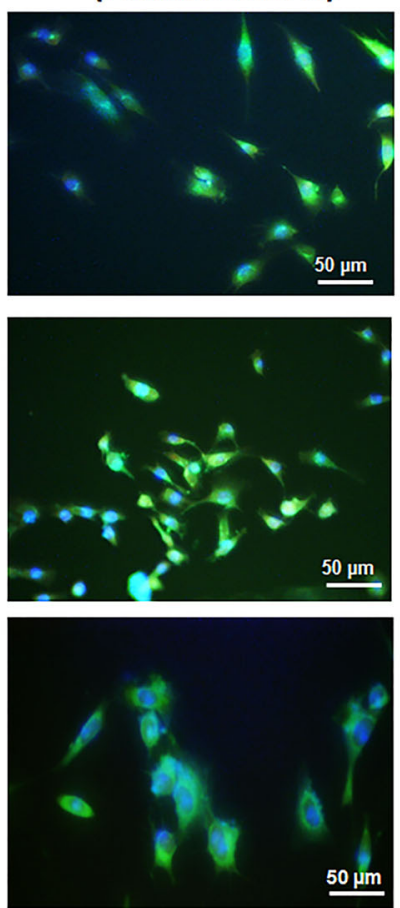

MSCs

(Negative control)
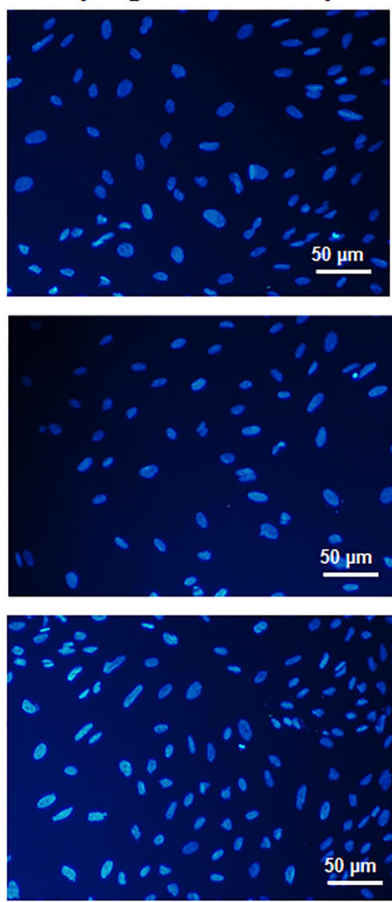

Fig. 6 (See legend on next page.) 
(See figure on previous page.)

Fig. 6 Morphology of seeded stem cells isolated from mice on day 0 and differentiated mesenchymal stem cells to keratinocyte type on day 18 in differentiating media. b Flow cytometry histograms of MSCs stained with fluorescein conjugated antibody. Black: without staining; red: stained cells (c) Expression of keratinocyte proteins including cytokeratin-19 (CK-19), involucrin (IVL) and vimentin (vim) after 18 days in differentiating media for MSC-derived keratinocytes, mice foreskin-derived keratinocytes as a positive control and MSCs in conventional culture medium. Nuclei were counterstained with DAPI

The decrease in size of the wound area in comparison to its original size was $87.4 \pm 3.4 \%$ for Ch-PVA + Silk fibrous mat with MSC-derived keratinocytes, $79.1 \pm$ $4.1 \%$ for Ch-PVA + Silk fibrous mat while it was only $57.2 \pm 5.4 \%$ for the paraffin sterile gauze condition at the 14th day. High degrees of wound healing suggest that the Ch-PVA + Silk fibrous mat due to worthy moisture condition and distinctive hemostatic properties could actively promote wound healing process with higher degrees of re-epithelialization $[16,19,20$, $27,28,32]$.

Histological analysis of the wounds in the paraffin sterile gauze group displayed evident leukocyte infiltration, granulation tissue formation, and a crusty scab, however, epidermal layer has not been formed (Fig. 8b). Histopathological evaluation of Ch-PVA + Silk group showed moderate infiltration of inflammatory cells into the wound area (Fig. 8b). Although, the epithelialization process was initiated, this process was incomplete in all samples in this group and the epithelial layer was thinner than normal skin. The inflammatory cells were significantly reduced at Ch-PVA + Silk group in comparison to paraffin sterile gauze group. Besides, we did not observed wound infection for treated conditions. It is expected that the antimicrobial effect of Ch due to destabilization of the outer membrane of gramnegative bacteria and permeabilization of the microbial plasma membrane be the reson for obtained results [3, 29, 36-39]. However the antibacterial effect and possible mechanism of the combination therapy is required to study through agar plate method and bacteriostatic ring test $[38,40]$.

Histopathological evaluation of the wounds treated by Ch-PVA + Silk fiber with MSC-derived keratinocyte group showed a considerable reduction of inflammatory cells in comparison to the other groups (Fig. 8b). A complete epithelial layer with the presence of rete ridges was formed in Ch-PVA + Silk fibrous mat containing cells. This group showed more resemblance to normal skin, with a thin epidermis (normal thickness of skin layers), presence of normal rete ridges, rejuvenation of the hair follicles (skin appendages). It seems that this treatment showed the best results while compared to other experimental groups. It is reported that keratinocytes play a vital role in epidermal restoration during wound healing through proliferation, migration and reepithelialization. The differentiated MSC to keratinocyte would implement its impact through provision of structural support, protection of epithelial cells from

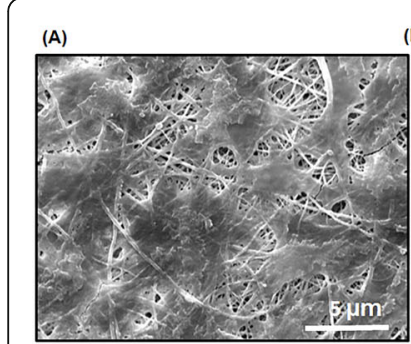

(E)

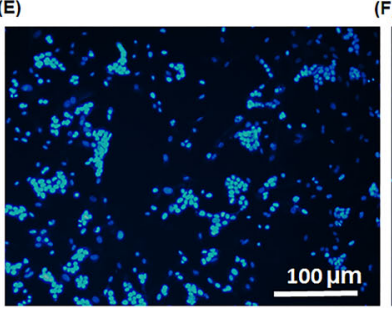

(B)

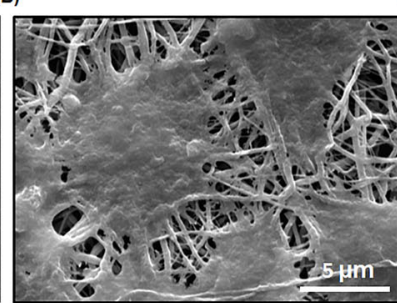

(F)

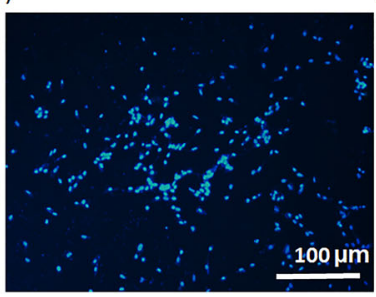

(C)

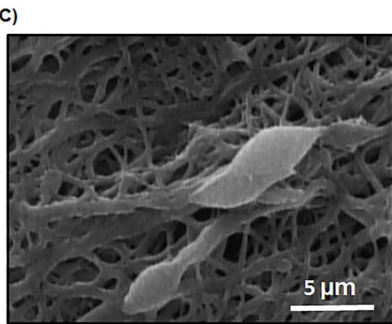

(G)

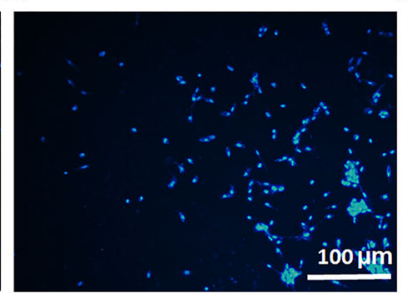

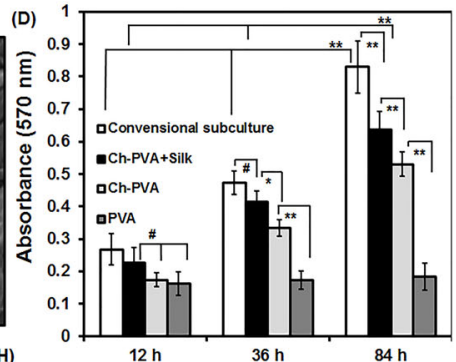

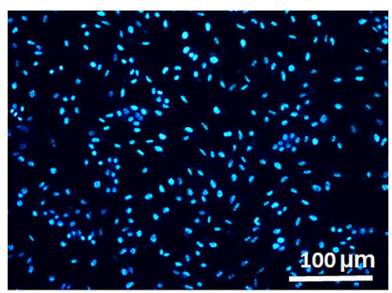

Fig. 7 a, b, c SEM photograph of MSC-derived keratinocytes attachment on fiber mats after $84 \mathrm{~h}$ seeding. $\mathbf{d}$ Cellular growth of seeded keratinocyte in PVA, Ch-PVA, Ch-PVA + Silk fibrous mats determined by MTT. e, $\mathbf{f}, \mathbf{g}, \mathbf{h}$ Fluorescence image of the DAPI stained nuclei of differentiated MSCs to keratinocyte after $84 \mathrm{~h}$ seeding. $\mathbf{a}$ and $\mathbf{e}$ Ch-PVA + Silk fibrous mat, (b and $\mathbf{f}$ ) Ch-PVA fibrous mat, (c and $\mathbf{g}$ ) PVA fibrous mat and (h) conventional subculture plate (Control). (Vertical bars: StdDv, $n=4,{ }^{*} p<.05,{ }^{*} p<.01$, and \#: stand for not significant differences). 


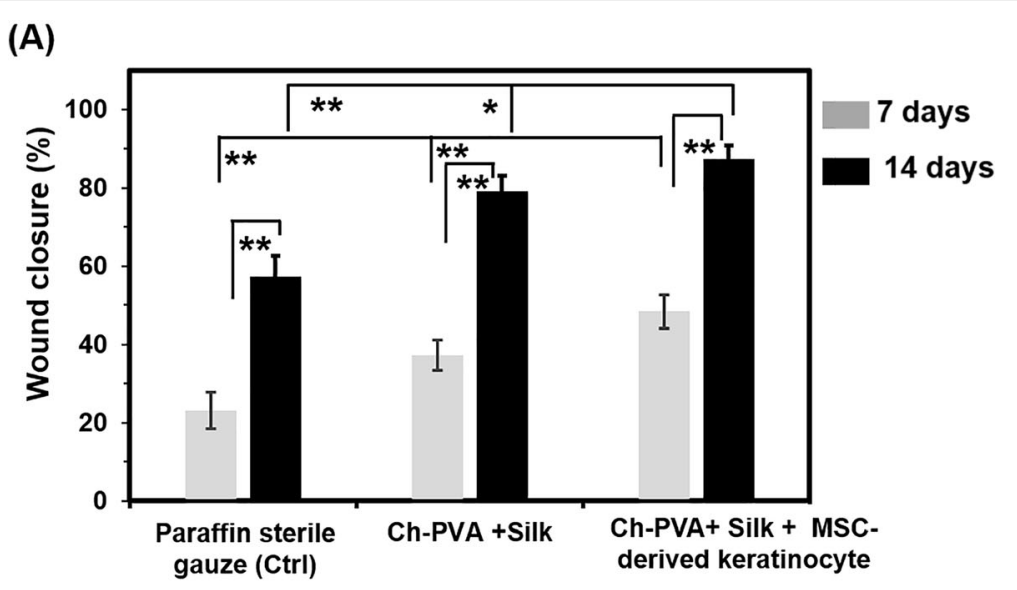

(B)
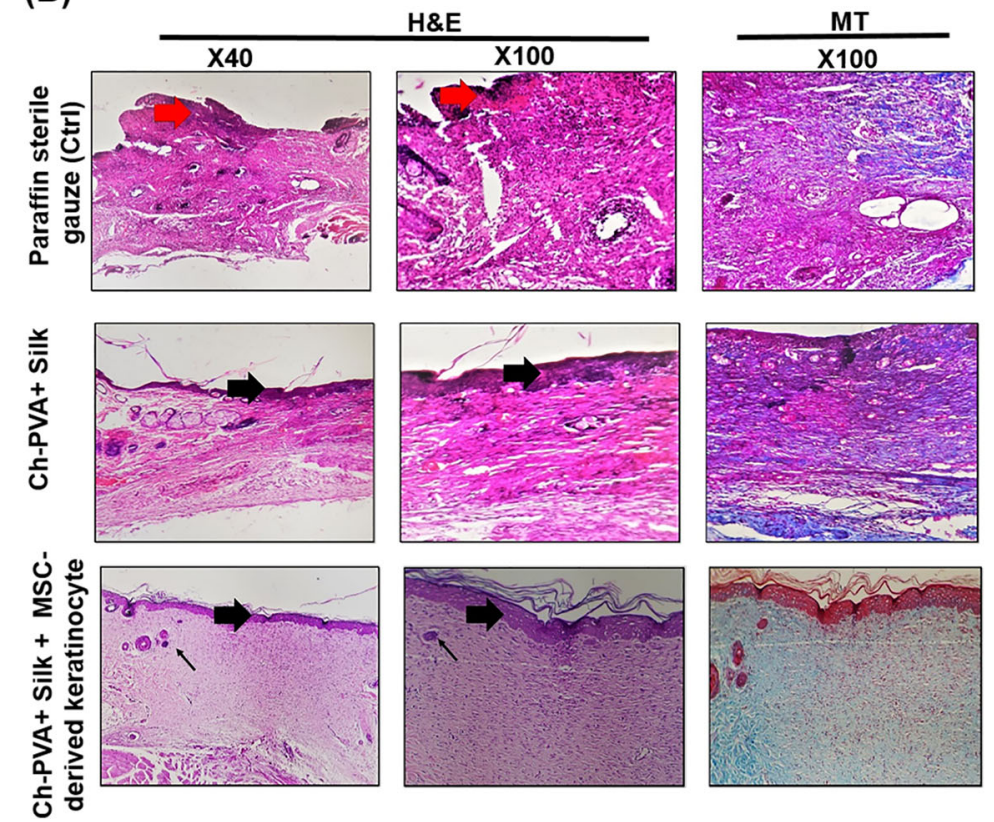

Fig. 8 a Quantity of wound contraction of experimental groups at different times (b) H\&E and MT stained microscopic sections of healed incisions at 14 days' post-treatment, Red thick arrows: crusty scab, thin arrows: rejuvenating of hair follicles (skin appendages), Black thick arrows: re-epithelializatfion

mechanical and non-mechanical stress and the regulation of apoptosis and protein synthesis [23, 40]. The wound healing process is heavily dependent on collagen synthesis. Therefore, to further investigate the effect of different treatments on wound healing, sections of animal skin tissues were stained with MT staining. This staining was used to recognize the progress of collagen synthesis during granulation tissue (GT) formation and matrix remodeling. The collagen fibers were stained blue-green in MT staining method which the intensity of this color corresponds to the relative amount of deposited total collagen and reflects the advancement of collagen synthesis and remodeling [13, 14, 16, 33, 36].
The results indicated that among the experimental groups, the Ch-PVA + Silk with MSC-derived keratinocyte group had the greatest collagen synthesis. On the other hand, the rate of collagen fiber synthesis and deposition in wound were the lowest in paraffin sterile gauze group.

\section{Histomorphometric analysis}

The histomorphometric analysis was done and the results have been presented in Tables 2 and 3. Amongst all groups, re-epithelialization in control groups was minimum and it was mostly filled with immature GT formation. The best re-epithelialization was seen in the 
Table 2 Histomorphometric analysis of different experimental groups

\begin{tabular}{ll}
\hline Groups & Epitheliogenesis Score \\
\hline Ctrl & 0 \\
Ch-PVA + Silk & 1 \\
Ch-PVA + Silk + MSC-derived keratinocytes & 4 \\
\hline
\end{tabular}

Ch-PVA + Silk + MSC-derived keratinocyte treatment group. Moreover, the total number of inflammatory cells in Ch-PVA + Silk + MSC-derived keratinocyte treatment group was significantly reduced in comparison with others $(P$-value $<0.01)$. Overall, the healing results of Ch-PVA + Silk + MSC-derived keratinocyte treatment group was more similar to that of the normal skin with normal thickness of epidermal layer and rejuvenation of the hair follicles and other skin appendages.

\section{Conclusion}

This study was designed to develop hybrid fiber mat compose of Ch, PVA and silk through co-electrospining process to evaluate their synergic effect on wound healing process. The physical and biochemical specification of fabricated hybrid fibrous mat were investigated. The effect of composition on structure, morphology, hydrophilicity and mechanical properties of the fibers were also studied. The Ch-PVA + Silk hybrid fiber prominently showed superior mechanical properties and desire swelling as well as hydrophilic microenvironment to those of pure PVA and Ch-PVA fibers. Incorporation of blended $\mathrm{Ch}$ and co-electrospun silk in PVA based fibrous mat presented excellent cell adhesion and proliferation in comparison to the neat PVA and Ch-PVA fibers. The in vivo study showed that composite $\mathrm{Ch}$ PVA + Silk fibrous mat in presence of MSC-derived keratinocytes could stimulate wound healing and skin tissue regeneration. These components are structurally and morphologically suitable for stem cell culture and application in tissue engineering because of their biophysical properties and cytocompatibility.

Table 3 Histomorphometric analysis of wounds

\begin{tabular}{llll}
\hline Groups & $\begin{array}{l}\text { Inflammatory } \\
\text { cells }\end{array}$ & $\begin{array}{l}\text { Blood } \\
\text { vessels }\end{array}$ & $\begin{array}{l}\text { Collagen } \\
\text { content }\end{array}$ \\
\hline Ctrl & $84.6 \pm 9.0$ & $26.2 \pm 4.1$ & $23 \pm 5.1$ \\
Ch-PVA + Silk & $49 \pm 5.5^{* *}$ & $19.7 \pm 2.5$ & $31.2 \pm 2.8^{*}$ \\
Ch-PVA + Silk + MSC-derived & $13 \pm 2^{* * *}$ & $6.2 \pm 1.7^{* * *}$ & $79.7 \pm 2.9^{* * *}$ \\
keratinocytes & & & \\
\hline
\end{tabular}

$* *^{* *}, * * *$ values indicate treatment group versus un-treatment group (empty control); ${ }^{* *} P$-value $<0.01,{ }^{* * *} P$-value $<0.001$

\begin{abstract}
Abbreviations
PVA: Polyvinyl alcohol; Ch: Chitosan; ECM: Extracellular matrix;

CMC: Carboxymethyl cellulose; HA: Hyaluronic acid; FDA: Food and drug administration; Ala: Alanine; Gly: Glycine; Ser: Serine; Asp: Aspartic acid; GAG: Glycosaminoglycan; DAPI: 4',6-diamidino-2-phenylindole; MSCs: Mesenchymal stem cells; CK-19: Cytokeratin-19; IVL: Involucrin; Vim: Vimentin; MTT: 3-[4,5-dimethyl-2-thia-zolyl]-2, 5-diphenyl-2H-tetrazolium bromide; GT: Granulation tissue; MT: Masson's trichrome; H\&E: Hematoxylin and eosin; EGF: Epidermal growth factor; KGF: Keratinocyte growth factor
\end{abstract}

\section{Acknowledgments}

Not applicable.

\section{Authors' contributions}

$A F, Z A$ and $A G$ performed all experimental work. MK participated in characterization of data. LF, ZTM and JS contributed to the cellular study and molecular analysis. MK and JA committed in study design, data collection and analysis and also the edition of the manuscript. All authors read and approved the final manuscript.

\section{Funding}

Not Applicable

\section{Availability of data and materials}

The datasets used and/or analyzed during the current study are available from the corresponding author on reasonable request.

\section{Ethics approval and consent to participate}

Animals use and care were approved with national ethics committee of Tehran University of Medical Sciences (ethical code:

IR.TUMS.IKHC.REC.1399.219) and were performed in accordance with the university's guidelines. Furthermore, all animal experiments comply with the National Institutes of Health guide for the care and use of laboratory animals (NIH Publications No. 8023, revised 1978).

\section{Consent for publication}

This manuscript contains no details, or videos relating to an individual person so that this section is not applicable.

\section{Competing interests}

The authors declare that they have no competing interests.

\section{Author details}

'Department of Plastic and Reconstructive Surgery, School of Medicine, Tehran University of Medical Sciences, Tehran, Iran. ${ }^{2}$ Skull Base Research Center, The Five Senses Institute, Hazrat Rasoul Akram Hospital, Iran University of Medical Sciences (IUMS), Tehran, Iran. ${ }^{3}$ Department of Tissue Engineering and Applied Cell Sciences, School of Advanced Technologies in Medicine, Fasa University of Medical Sciences, Fasa, Iran. ${ }^{4}$ Tehran University of Medical Sciences, Tehran, Iran. ${ }^{5}$ Department of Tissue Engineering and Applied Cell Sciences, School of Advance Technologies in Medicine, Tehran University of Medical Sciences, Tehran 1417743361, Iran. ${ }^{6}$ Department of Biomedical and Electronics Engineering, School of Engineering, University of Bradford, Bradford, UK. ${ }^{7}$ Brain and Spinal Cord Injury Research Center, Neuroscience Institute, Tehran University of Medical Sciences, Tehran, Iran.

Received: 29 June 2020 Accepted: 5 November 2020

Published online: 18 November 2020

References

1. Chen $\mathrm{S}$, et al. Recent advances in electrospun nanofibers for wound healing. Nanomedicine. 2017;12(11):1335-52..

2. Kamoun EA, Kenawy E-RS, Chen X. A review on polymeric hydrogel membranes for wound dressing applications: PVA-based hydrogel dressings. J Adv Res. 2017;8(3):217-33..

3. Garakani SS, et al. Fabrication of chitosan/agarose scaffolds containing extracellular matrix for tissue engineering applications. Int J Biol Macromol. 2020;143:533-45..

4. Bordbar S, et al. Production and evaluation of decellularized extracellular matrix hydrogel for cartilage regeneration derived from knee cartilage. J Biomed Mater Res A. 2020;108(4):938-46. 
5. Yeo JH, et al. The effects of PVA/chitosan/fibroin (PCF)-blended spongy sheets on wound Heailng in rats. Biol Pharm Bull. 2000;23(10):1220-3.

6. Nemati S, et al. Current progress in application of polymeric nanofibers to tissue engineering. Nano Convergence. 2019:6(1):36.

7. Bagheri S, et al. Control of cellular adhesiveness in hyaluronic acid-based hydrogel through varying degrees of phenol moiety crosslinking. J Biomed Mater Res A. 2020. p. 1-10. https://doi.org/10.1002/jbm.a.37049.

8. Fathollahipour $\mathrm{S}$, et al. Electrospinning of PVA/chitosan nanocomposite nanofibers containing gelatin nanoparticles as a dual drug delivery system. J Biomed Mater Res A. 2015;103(12):3852-62.

9. Khanmohammadi $M$, et al. Cell encapsulation in core-shell microcapsules through coaxial electrospinning system and horseradish peroxidase-catalyzed crosslinking. Biomed Phys Eng Express. 2020;6(1): 015022.

10. Sheik S, et al. Study on the morphological and biocompatible properties of chitosan grafted silk fibre reinforced PVA films for tissue engineering applications. Int J Biol Macromol. 2018;116:45-53.

11. Majd SA, et al. Application of chitosan/PVA Nano fiber as a potential wound dressing for streptozotocin-induced diabetic rats. Int J Biol Macromol. 2016; 92:1162-8.

12. Wang M, Roy AK, Webster TJ. Development of chitosan/poly (vinyl alcohol) electrospun nanofibers for infection related wound healing. Front Physiol. 2017;7:683.

13. Lin J, et al. Co-electrospun nanofibrous membranes of collagen and zein for wound healing. ACS Appl Mater Interfaces. 2012;4(2):1050-7.

14. Kweon $\mathrm{H}$, et al. Physical properties of silk fibroin/chitosan blend films. J Appl Polym Sci. 2001;80(7):928-34.

15. ÜSTÜNDAĞ GC, et al. In vivo evaluation of electrospun poly (vinyl alcohol)/ sodium alginate nanofibrous mat as wound dressing. Tekstil ve Konfeksiyon. 2010;20(4):290-8.

16. $\mathrm{Li} \mathrm{J}$, et al. Electrospinning of hyaluronic acid $(\mathrm{HA})$ and $\mathrm{HA} /$ gelatin blends. Macromol Rapid Commun. 2006;27(2):114-20.

17. Shafei $\mathrm{S}$, et al. Exosome loaded alginate hydrogel promotes tissue regeneration in full-thickness skin wounds: an in vivo study. J Biomed Mater Res A. 2019;108A:545-56.

18. ElMessiry M, Fadel N. The tensile properties of electrospun poly vinyl chloride and cellulose acetate (PVC/CA) bi-component polymers nanofibers. Alexandria Eng J. 2019:58(3):885-90

19. Bahrami S, Nouri M. Chitosan-poly (vinyl alcohol) blend nanofibers: morphology, biological and antimicrobial properties. e-Polymers. 2009;133: $1-12$.

20. Lin H-Y, et al. Pectin-chitosan-PVA nanofibrous scaffold made by electrospinning and its potential use as a skin tissue scaffold. J Biomater Sci Polym Ed. 2013;24(4):470-84.

21. Shao W, et al. Enhanced bone formation in electrospun poly (I-lactic-coglycolic acid)-tussah silk fibroin ultrafine nanofiber scaffolds incorporated with graphene oxide. Mater Sci Eng C. 2016;62:823-34.

22. Zafar B, et al. Silk fibroin/alumina nanoparticle scaffold using for osteogenic differentiation of rabbit adipose-derived stem cells. Materialia. 2020;9: 100518

23. Zhang $D$, et al. Helicobacter pylori ribosomal protein-A2 peptide/silk fibroin nanofibrous composites as potential wound dressing. J Biomed Nanotechnol. 2019:15(3):507-17.

24. Gaspar A, et al. Human adipose-derived stem cells differentiation into epidermal cells and interaction with human keratinocytes in coculture. Turk J Biol. 2016;40(5):1111-20.

25. dos Santos JF, et al. Mesenchymal stem cells differentiate into keratinocytes and express epidermal kallikreins: towards an in vitro model of human epidermis. J Cell Biochem. 2019;120(8):13141-55.

26. Pervez M, Stylios GK. Investigating the synthesis and characterization of a novel "green" H2O2-assisted, water-soluble chitosan/polyvinyl alcohol nanofiber for environmental end uses. Nanomaterials. 2018;8(6):395.

27. Sheik $\mathrm{S}$, et al. Development and characterization study of silk fibre reinforced poly (vinyl alcohol) composites. Int J Plast Technol. 2017;21(1): 108-22.

28. Wali A, et al. Electrospinning of non-ionic cellulose ethers/polyvinyl alcohol nanofibers: characterization and applications. Carbohydr Polym. 2018;181: 175-82

29. Zahiri $\mathrm{M}$, et al. Encapsulation of curcumin loaded chitosan nanoparticle within poly ( $\varepsilon$-caprolactone) and gelatin fiber mat for wound healing and layered dermal reconstitution. Int J Biol Macromol. 2019;153:1241-50.
30. Khanmohammadi M, Sakai S, Taya M. Fabrication of single and bundled filament-like tissues using biodegradable hyaluronic acid-based hollow hydrogel fibers. Int J Biol Macromol. 2017;104:204-12.

31. Khanmohammadi $\mathrm{M}$, et al. Multipotency expression of human adipose stem cells in filament-like alginate and gelatin derivative hydrogel fabricated through visible light-initiated crosslinking. Mater Sci Eng C. 2019;103:109808.

32. Ravichandran $R$, et al. Click chemistry approach for fabricating PVA/gelatin nanofibers for the differentiation of ADSCs to keratinocytes. J Mater Sci Mater Med. 2013;24(12):2863-71.

33. Jin G, Prabhakaran MP, Ramakrishna S. Stem cell differentiation to epidermal lineages on electrospun nanofibrous substrates for skin tissue engineering. Acta Biomater. 2011;7(8):3113-22

34. Garakani SS, et al. Fabrication of chitosan/polyvinylpyrrolidone hydrogel scaffolds containing PLGA microparticles loaded with dexamethasone for biomedical applications. Int J Biol Macromol. 2020;164:356-70.

35. Astaneh ME, et al. Chitosan/gelatin hydrogel and endometrial stem cells with subsequent atorvastatin injection impact in regenerating spinal cord tissue. J Drug Deliv Sci Technol. 2020:101831.

36. Nooshabadi VT, et al. Impact of exosome loaded chitosan hydrogel in wound repair and layered dermal reconstitution in mice animal model. J Biomed Mater Res A. 2020;108:2138-49.

37. Zhu C, et al. Skin derived precursor Schwann cell-generated acellular matrix modified chitosan/silk scaffolds for bridging rat sciatic nerve gap. Neurosci Res. 2018;135:21-31.

38. Gao G, et al. Near-infrared light-controllable on-demand antibiotics release using thermo-sensitive hydrogel-based drug reservoir for combating bacterial infection. Biomaterials. 2019;188:83-95.

39. Majid Salehi SZ. Hadi Samadian, Jafar Ai, Laleh Foroutani, Arman Ai, Mehd Khanmohammadi, Chitosan hydrogel containing Aloe vera gel and Tetrasodium EDTA as the wound healing material: in vitro and in vivo study. J Appl Polym Sci. 2020. https://doi.org/10.1002/app.50225.

40. ter Horst B, et al. Advances in keratinocyte delivery in burn wound care Adv Drug Deliv Rev. 2018;123:18-32.

\section{Publisher's Note}

Springer Nature remains neutral with regard to jurisdictional claims in published maps and institutional affiliations.
Ready to submit your research? Choose BMC and benefit from:

- fast, convenient online submission

- thorough peer review by experienced researchers in your field

- rapid publication on acceptance

- support for research data, including large and complex data types

- gold Open Access which fosters wider collaboration and increased citations

- maximum visibility for your research: over $100 \mathrm{M}$ website views per year

At $\mathrm{BMC}$, research is always in progress.

Learn more biomedcentral.com/submissions 